\title{
Planejamento urbano-ambiental: percepção da população sobre o parque zoológico de Goiânia
}

\author{
Urban-environmental planning: the population's perception about the Goiânia zoo park \\ Planificación urbano-ambiental: la percepción de la población sobre el parque zoológico de Goiânia
}

Recebido: 29/08/2021 | Revisado: 04/09/2021 | Aceito: 24/09/2021 | Publicado: 25/09/2021

Cibele de Moura Guimarães

ORCID: https://orcid.org/0000-0002-9976-7206

Núcleo Integrado de Educação a Distância, Brasil

E-mail: cibelego@hotmail.com

Antônio Pasqualetto

ORCID: https://orcid.org/0000-0002-8639-6725

Pontifícia Universidade Católica de Goiás, Brasil Instituto Federal de Educação, Ciência e Tecnologia de Goiás, Brasil E-mail: profpasqualetto@gmail.com

Alexandre Thomáz Magalhães

ORCID: https://orcid.org/0000-0002-1144-9554

Instituto Federal de Educação, Ciência e Tecnologia de Goiás, Brasil

E-mail: alexandrefragali@gmail.com

\begin{abstract}
Resumo
Objetivou-se avaliar os aspectos urbanos e ambientais, analisando a percepção da sociedade no Parque Zoológico de Goiânia em 2018. A metodologia dividiu-se em objeto, tipo de classificação e etapas da pesquisa: a) evolução e ocupação do solo urbano; b) caracterização do zoológico pelo instrumento do geoprocessamento; c) percepção da sociedade em relação ao Parque Zoológico. Utilizou-se registros fotográficos, projetos do Parque Zoológico, geoprocessamento de imagens satélites do Google Earth Pro, plataforma on-line Mapa Urbano Básico Digital de Goiânia, softwares Qgis e Google Earth e aplicou-se questionário à população para analisar variáveis ambientais. Os resultados demonstraram que desde sua criação, o zoológico recebeu adequações de melhoria nos recintos dos animais e na alimentação, bem como reflorestamento. A localização é de fácil acesso, mas sofre pressões pela ocupação por edificações em seu entorno. Dentre as propostas sugeridas destaca-se ter um parque apenas com animais do Cerrado ou modelo Safari em Goiânia.
\end{abstract}

Palavras-chave: Impactos ambientais; Percepção da sociedade; Uso e ocupação do solo; Zoológico.

\begin{abstract}
The objective was to evaluate urban and environmental aspects, analyzing the perception of society in the Parque Zoológico de Goiânia in 2018. The methodology was divided into object, type of classification and stages of the research: a) evolution and occupation of urban land; b) characterization of the zoo by the geoprocessing instrument; c) society's perception of the Zoological Park. Photographic records, Zoological Park projects, geoprocessing of Google Earth Pro satellite images, on-line Digital Basic Urban Map of Goiânia, Qgis and Google Earth software were used, and a questionnaire was applied to the population to analyze environmental variables. The results showed that since its creation, the zoo has received improvements to improve the animal enclosures and food, as well as reforestation. The location is easy to access, but suffers pressure from the occupation of buildings in its surroundings. Among the suggested proposals, we highlight having a park with only animals from the Cerrado or Safari model in Goiânia.
\end{abstract}

Keywords: Environmental impacts; Perception of society; Land use and occupation; Zoo.

\section{Resumen}

El objetivo fue evaluar aspectos urbanos y ambientales, analizando la percepción de la sociedad en el Parque Zoológico de Goiânia en 2018. La metodología se dividió en objeto, tipo de clasificación y etapas de investigación: a) evolución y ocupación del suelo urbano; b) caracterización del zoológico por el instrumento de geoprocesamiento; c) la percepción que tiene la sociedad del Zoo. Se utilizaron registros fotográficos, proyectos de parques zoológicos, geoprocesamiento de imágenes satelitales de Google Earth Pro, plataforma en línea Digital Basic Urban Map de Goiânia, Qgis y software Google Earth, y se aplicó un cuestionario a la población para analizar variables ambientales. Los resultados mostraron que desde su creación, el zoológico ha recibido mejoras en los recintos de animales y alimentos, así como en la reforestación. La ubicación es de fácil acceso, pero está sometida a la presión de la ocupación por parte de los edificios de sus alrededores. Entre las propuestas sugeridas, destaca un parque con solo animales del modelo Cerrado o Safari en Goiânia.

Palabras clave: Impactos ambientales; Percepción de la sociedad; Uso y ocupación del suelo; Zoo. 


\section{Introdução}

$\mathrm{O}$ ordenamento do espaço urbano compreende o planejamento do ecossistema das cidades, incluindo os meios sociais, econômicos, físicos e ambientais. O desenvolvimento disso está voltado por meio das questões da sustentabilidade, respeito à sociedade e ao meio natural em que está inserida. Com o passar do tempo, houve crescimento desordenado dos centros urbanos, ocasionando desorganização no espaço das cidades provocando impactos, gerando problemas sociais, ambientais e econômicos. Como exemplo, perda da qualidade de vida dos seres vivos, poluição de ar e ruídos e outros. Leal, Carrerá e Pereira (2021) afirmam que a urbanização desenfreada, sem base de planejamento, a problemática ambiental se agrava e ganha escopo cada vez mais à medida que as cidades se expandem.

Dentre as mais graves e adversas implicações para a ecologia provenientes da urbanização acelerada e sem o adequado planejamento está o aumento das áreas construídas, a impermeabilização do solo e a consequente redução das áreas de vegetação natural, áreas úmidas e corpos hídricos (Patra, Sahoo, Mishra \& Mahapatra, 2018).

Uma das formas para adequar os centros urbanos são formulações de políticas públicas relacionadas ao uso e a ocupação do solo urbano, objetivando contribuir para a construção de ambientes equilibrados, mais justos e menos degradantes do meio ambiente natural. Martins, Salles, Macedo, Nunes e Ribeiro (2020) afirmam que "as cidades absorvem a maior parte da população mundial. Nesse sentido, as mesmas devem buscar maior qualidade de vida dessa população crescente, através da promoção de espaços mais sustentáveis" (p.1). O ordenamento dos espaços públicos, sobretudo os de lazer, a exemplo do Zoológico, é um dos aspectos vitais na revitalização e na qualidade de vida no meio urbano. Os processos de formação das cidades, expansão e segregação socioespacial, estão dentro de um contexto natural de avanço urbano, a exemplo da Região Metropolitana de Goiânia. Neste sentido, surge a questão: como está inserido o Zoológico no planejamento urbano e ambiental de Goiânia?

Silva (2017) define planejamento urbano como um processo técnico e político com vistas à organização de orientações futuras para uma cidade, usando diversos meios para alcançar os objetivos propostos; isto é, são as ações propostas visando a orientar e assegurar o desenvolvimento ordenado da cidade, direcionando o desenho do ambiente urbano, o uso e a ocupação do solo. Leal, Carrerá e Pereira (2021) afirma que "para diagnosticar a qualidade ambiental urbana com a intenção de propor melhorias, faz-se necessária a articulação entre conceitos e teorias nas diversas áreas do conhecimento científico" (p.4).

Para tanto, indicadores são ferramentas indispensáveis para análise e tomada de decisões. Segundo Macedo, Cândido, Costa e Silva (2016, p. 331), indicadores são como "ferramentas constituídas por uma ou mais variáveis que se associam e oferecem significados mais amplos sobre determinado fenômeno". Ainda é uma representação de um atributo, podendo ser qualidade, característica, propriedade, com a finalidade de agregar quantitativamente as variáveis analisadas, ressaltando sua significância (Bellen, 2005).

Por esse motivo, Leal, Carrerá e Pereira (2021) define que indicadores são ferramentas utilizadas para auxiliar no monitoramento da operacionalização do desenvolvimento sustentável. O conceito de sustentabilidade é complexo e compreende diversas dimensões, refletindo no processo de construção dos indicadores. Nesse artigo, destacou-se a dimensão social e ambiental (Macedo, Cândido, Costa \& Silva, 2016, p. 331).

$\mathrm{O}$ processo de degradação ambiental está ligado a fatores naturais e antrópicos, principalmente a fatores antrópicos como o processo de ocupação humana (Silva, Vidal, Barros \& Freitas, 2018).

Precisa-se planejar, buscar, estruturar o futuro da cidade, para que não torne problema tanto nos cenários sociais, urbanos e ambientais.

Com essa pesquisa, analisou-se indicadores socioambientais, o nível de satisfação dos visitantes e moradores do entorno do Parque Zoológico de Goiânia, bem como diagnosticar o atual cenário do equipamento urbano. 


\section{Metodologia}

Na sequência são apresentados o objeto de pesquisa, classificação da pesquisa, o universo e amostra, bem como a confecção e aplicação do instrumento de coleta de dados.

\subsection{Objeto da pesquisa}

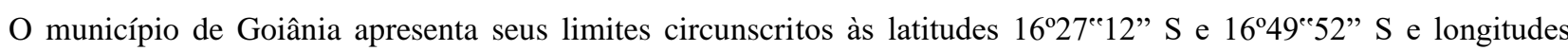
$49^{\circ} 4^{\prime \prime 3} 3 "$ O e $49^{\circ} 26^{\circ “ 48^{\prime \prime}} \mathrm{O}$, totalizando uma área de $732 \mathrm{~km}^{2}$ (Nascimento \& Oliveira, 2015), confluência das ruas Alameda das Rosas e norte com a Avenida Anhanguera, Setor Oeste, referiu-se ao Parque Zoológico de Goiânia. As altitudes variam de 661 a 1.037 m acima do nível do mar, com média de 785 m. Sua população foi estimada, para 2019, em 1.516.113 habitantes (IBGE, 2017). Na imagem satélite mostra o Parque Zoológico implantado em área anexa ao parque urbano Lago das Rosas, e dentro do Zoológico localiza-se a nascente do córrego Capim Puba (Figura 1).

Figura 1 - Goiânia (GO): Localização do objeto da pesquisa - Parque Zoológico, 2019.

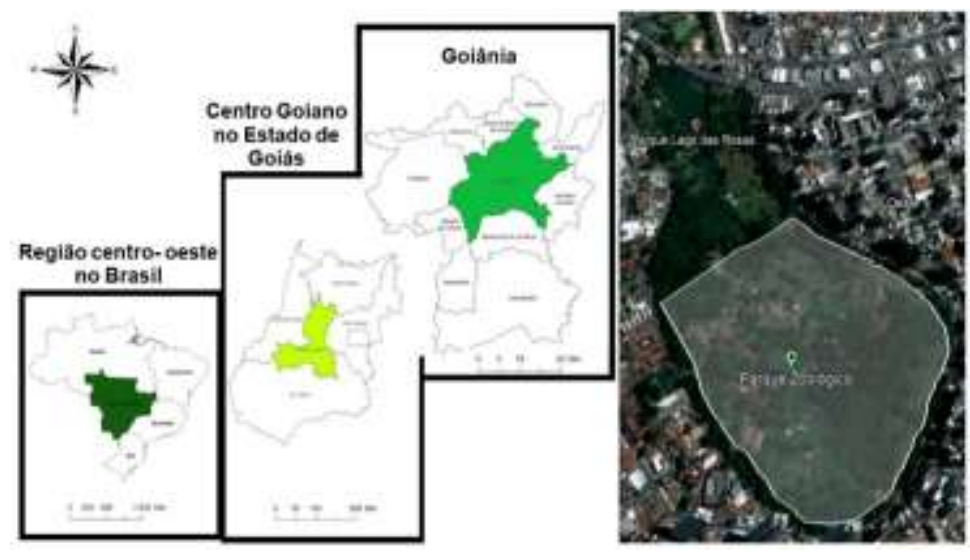

Fonte: Base Cartográfica do IBGE e Google Earth adaptado pela autora (2018).

Para o estudo do Parque Zoológico, apresenta-se a classificação da pesquisa para identificar o melhor meio para a organização das ideias e coletas de dados.

\subsection{Classificação da Pesquisa}

A pesquisa foi classificada como exploratória, abordando análise urbana e ambiental, detectando a visão dos moradores do entorno, visitantes do parque, ainda pesquisa em campo para coleta de dados, conforme Severino (2016, p. 131), feita "nas condições naturais em que os fenômenos ocorrem, sendo assim diretamente observados, sem intervenção e manuseio por parte do pesquisador, abrangendo processo de levantamentos.

\subsection{Universo e Amostra}

O universo da pesquisa foram os moradores do entorno e visitantes, envolvendo dois grupos amostrais na aplicação de questionários. Para definir a amostragem adotou-se o fluxo de visitantes do Parque Zoológico de Goiânia, sendo o fluxo médio anual de 264.000 pessoas. Em seguida, definiu-se a amostragem pelo método estatístico da determinação do tamanho da amostra com base na estimativa da proporção populacional. Dada a população, considerou-se amostra infinita. Conforme Levine (2000) a fórmula utilizada é:

$$
\begin{gathered}
\text { (Equação 1) } \\
\mathrm{n}=\mathrm{Z}_{\alpha / 2}^{2} \cdot \mathrm{p} \cdot \mathrm{q}
\end{gathered}
$$


Onde:

$\mathrm{n}=$ número de indivíduos na amostra, ou seja, tamanho da amostra.

$\mathrm{Z} \alpha / 2=$ valor crítico que corresponde ao grau de confiança desejado.

$\mathrm{p}=$ proporção populacional de indivíduos que pertence a categoria estudada.

$\mathrm{q}=$ proporção populacional de indivíduos que não pertence à categoria estudada $(\mathrm{q}=1-\mathrm{p})$.

$\mathrm{E}=$ margem de erro ou erro máximo de estimativa. Identifica a diferença máxima entre a proporção amostral e a verdadeira proporção populacional (p).

De acordo com Levine (2000), quando não há condições de prever os valores populacionais p e q, deve-se substituir por valores amostrais $\hat{p}$ e $\hat{q}$, ainda admitir que para cada um desses valores seja igual a 0,5 , pois são desconhecidos. Obtendo a fórmula abaixo:

$$
\begin{gathered}
\text { (Equação 2) } \\
\mathrm{n}=\mathrm{Z}_{\alpha / 2}^{2} \cdot \hat{p} \text { e } \hat{q}
\end{gathered}
$$

Posteriormente, comparou-se o tamanho da amostra da equação 2 pelo tamanho da população (N). Conforme Levine (2000), caso a amostra tenha tamanho (n) maior ou igual a 5\% do tamanho da população (N), considera-se que a população seja FINITA. Para isso utilizou-se por meio de tentativas os três valores de critérios e $\alpha$ da Tabela 1 para realizar a comparação. Em seguida, adotou-se $\alpha=0,10$ (90\% de confiança) devido ao tamanho da amostra ser menor a 5\% do tamanho da população e considerado amostra infinita.

Tabela 1 - Valores críticos associados ao grau de confiança na amostra.

\begin{tabular}{ccc}
\hline Grau de confiança & $\boldsymbol{\alpha}$ & Valor Crítico Za/2 \\
\hline $90 \%$ & 0,10 & 1,645 \\
$95 \%$ & 0,05 & 1,960 \\
$99 \%$ & 0,01 & 2,575 \\
\hline
\end{tabular}

Fonte: Levine (2000).

Neste caso, aplica-se o fator de correção, resultando das seguintes fórmulas corrigidas para determinar o tamanho da amostra (n) e baseando na estimativa da proporção populacional de Levine (2000), utilizando-se a equação 3:

$$
\mathrm{n}=\frac{\mathrm{N} \cdot \widehat{\mathrm{p}} \cdot \hat{\mathrm{q}} \cdot(\mathrm{Z} \alpha / 2)^{2}}{\widehat{\mathrm{p}} \cdot \hat{\mathrm{q}} \cdot(\mathrm{Z} \alpha / 2)^{2}+(\mathrm{N}-1) \cdot \mathrm{E}^{2}}
$$

Dessa forma, o tamanho da amostra foi de aproximadamente 70 pessoas, porém elaborou-se 80 questionários por margem de segurança, dividindo em 40 questionários de visitantes, 40 moradores do entorno do Parque Zoológico.

\subsection{Confecção e aplicação do instrumento de coleta de dados}

Após a definição do tamanho da amostra realizou-se visitas no entorno e nas proximidades do Parque Zoológico para realizar as coletas com os moradores e visitantes que frequentam o local.

O questionário foi estruturado em: caracterização dos visitantes e moradores, fatores ambientais, uso e ocupação do solo, cada um com os seus critérios de avaliação, sugestões de melhorias. Os questionários foram aplicados em meados dos 
meses de junho e julho em 2018, nas quintas e sextas-feiras para moradores, nos períodos vespertinos e noturno (15h às $19 \mathrm{~h})$. Aos finais de semana (sábado e domingo) para visitantes, no período matutino (9h30 às 11h30) e vespertino (14h às 16h). Para a caracterização tanto dos visitantes quanto dos moradores dividiu-se em sexo (masculino e feminino), grau de instrução (ensinos fundamental, médio, graduação e pós-graduação) e faixa etária ( 0 a 17; 18 a $29 ; 30$ a 49 e acima de 49 anos) esses foram respondidos fazendo escolhas de opções. Para fatores ambientais foram definidos em três segmentos: físico, biótico (fauna e flora) e antrópico, analisados por meio de indicadores ambientais. Para a avaliação do uso e ocupação do solo verificou-se opiniões sobre a existência, localização do Zoológico, como respostas para sim ou não, mas também analisou sobre modelo desse parque, respondendo sim ou não ou outro (Safari).

Para o segmento do meio físico utilizou-se indicadores: solo, qualidade da água dos lagos e ar; o meio biótico (fauna e flora), a qualidade de vida dos animais, estresse e confinamento para fauna e a biodiversidade vegetal, quantidade de árvores e conservação para flora. O terceiro, considerado meio antrópico, os indicadores analisados foram valorização imobiliária, paisagem urbana, tráfego, ventilação, qualidade de vida, odor e ruídos e para averiguar os riscos à saúde pública usou-se os indicadores urubu, febre amarela, dengue, Zica, Chikungunya, contaminação da água, fuga de animais, acidentes, quedas e afogamentos. Além disso, os visitantes e moradores propuseram sugestões para melhorias no Parque Zoológico.

Nos questionários dos visitantes e moradores utilizou-se critérios de análise dos indicadores ambientais e priorização dos impactos. Os critérios de análise dos indicadores foram escolhidos e adaptados de Montes e Filho (2009): fatores ambientais e impactos nos meios físico, biótico e antrópico. Adaptando Gomes, Peruzatto, Santos e Sellito (2014) e Vale, Toledo e Vieira (2018), adotando pesos, cores e nível de qualificação, sendo nível (ideal, 0, verde); (aceitável, 1, amarelo); (alerta, 2, vermelho) e (crítica, 3, preto). Para priorização dos impactos do nível de satisfação dos moradores e visitantes, multiplicou-se os critérios numéricos (pesos) pelo total de respostas em cada. Quanto maior valor obtido, maior gravidade do impacto.

Para a definição do índice ambiental relacionado aos impactos observados por meio de todos os indicadores analisados, considerou-se a quantidade de respostas ponderadas pelo valor do critério, encontrando-se a média final da gravidade dos impactos observados pelos moradores e visitantes. Além disso, houve questões abertas sobre Plano de Gerenciamento de Resíduos Sólidos e Uso e Ocupação do Solo.

Os resultados foram apresentados por meio de tabelas, gráficos e registros fotográficos, tendo seus dados confrontados com a literatura.

\section{Resultados e Discussão}

A caracterização dos 40 visitantes pesquisados foi de sexo feminino (18) e masculino (22), sendo pessoas com grau de instrução do ensino fundamental (5), médio (17), graduação (16) e pós-graduação (2) e as faixas etárias de 0 a 17 (5), 18 a 29 (15), 30 a 49 (12) e acima de $49 \operatorname{anos~(8).~A~caracterização~dos~} 40$ moradores pesquisados foi de sexo feminino (14) e masculino (26), sendo pessoas com grau de instrução do ensino fundamental (2), médio (22), graduação (9) e pós-graduação (7) e as faixas etárias de 0 a 17 (3), 18 a 29 (15), 30 a 49 (10) e acima de 49 anos (12). Nota-se que a maioria da amostra coletada corresponde a um público, em processo de ativação das percepções e ideias próprias.

Na Tabela 2 apresentou-se que a maioria (34) dos visitantes considera necessário o Parque Zoológico em Goiânia. Quanto a sua localização, 16 pessoas entendem ser o local inadequado, especialmente pelo confinamento dos animais. Em relação da visão sobre a existência ou não do Zoológico, 27 dos visitantes gostariam de um modelo Safari em Goiânia, ainda 7 disseram que os animais devem estar livres e com maior espaço. De acordo com a Organização Não Governamental SinZoo citado por Molina (2016), o mais importante é eliminar o modelo de exibição e cativeiro, por exemplo, modelo Safari, pois 
quando se comunica às crianças que não é correto prender animais, o zoo transmite mensagem cruel e contrária, bem como, é um equipamento urbano de lazer para as crianças aprenderem sobre a educação ambiental.

Já 31 moradores responderam que é necessário haver este local, porém 21 entendem que sua localização não está adequada. Dos 40, 27 preferem que em Goiânia devem ter um Zoológico Safari, porém 8 moradores, manifestaram o desejo de não existir Zoológico em Goiânia, pois animais devem estar livres e 5 foram a favor de animais no modelo preso (Tabela 2). Há depoimentos sobre zoológico Beto Carrero (Penha, SC) e Zoo safari (São Paulo) no modelo Safari no Brasil, estes relataram a ótima experiência de visitar o modelo Safari, pois interagiram, ficaram mais próximos dos animais e sentiram emoção de vê-los por perto, ainda de poder alimentá-los com ração vendida no próprio local, ressaltando-se de antes de fazer o passeio havia quadro informativo de segurança para não acontecer nenhum acidente com os visitantes e animais (Ribeiro, et al., 2009).

Tabela 2 - Goiânia (GO): Uso e ocupação do solo e sugestões dos visitantes e moradores para melhoria no Parque Zoológico, 2019.

\begin{tabular}{|c|c|c|c|}
\hline \multicolumn{4}{|c|}{ Visitantes } \\
\hline \multirow[b]{2}{*}{ Uso e ocupação do solo } & \multicolumn{3}{|c|}{ Critérios de Avaliação } \\
\hline & Sim & Não & Outro (Safari) \\
\hline Você acha necessário haver Parque Zoológico em Goiânia? & 34 & 06 & - \\
\hline Você considera o Parque Zoológico construído em local adequado? & 24 & 16 & - \\
\hline Ter Parque Zoológico no modelo de animais presos. & 06 & 07 & 27 \\
\hline \multicolumn{4}{|c|}{ Sugira melhoria ao Parque Zoológico } \\
\hline \multicolumn{4}{|c|}{$\begin{array}{l}\text { Mais segurança para os visitantes; melhorar os aspectos dos vidros das jaulas que estão embasados; } \\
\text { Manutenção das pontes da entrada do Parque Zoológico; informações sobre os animais (procedência, histórico, descrições); } \\
\text { Mais espaço para os animais; manutenção dos banheiros do zoológico; ter mais animais; } \\
\text { Zoológico ficar aberto por mais temp; mais limpeza retirando os urubus; ter girafas; mais bancos. }\end{array}$} \\
\hline \multicolumn{4}{|c|}{ Moradores } \\
\hline & \multicolumn{3}{|c|}{ Critérios de Avaliação } \\
\hline Uso e ocupação do solo & Sim & Não & Outro (Safari) \\
\hline Você acha necessário haver Parque Zoológico em Goiânia? & 31 & 9 & - \\
\hline Você considera o Parque Zoológico construído em local adequado? & 21 & 19 & - \\
\hline Ter Parque Zoológico no modelo de animais presos. & 05 & 8 & 27 \\
\hline
\end{tabular}

Sugira melhoria ao Parque Zoológico

Mudança de local, porque é obsoleto e inadequado, causando sofrimento aos animais.

Fonte: Autores (2019).

A Tabela 3 mostra o nível de satisfação dos visitantes para os três meios analisados: físico, biótico e antrópico. Analisando o meio biótico relacionada a fauna, na forma decrescente, obteve as seguintes avaliações: 23, 27 e 31 , respectivamente para os seguintes indicadores ambientais: qualidade de vida dos animais, estresse, confinamento, todos com visões críticas pelos visitantes.

Ressaltando-se que o maior valor analisado foi 31, ou seja, deve-se priorizar para planejar, criar e aplicar medidas a estes indicadores. Para a flora, situação foi considerada ideal, há biodiversidade vegetal, quantidade de árvores e conservação, com isso quanto maior concentração de vegetação, maior redução da temperatura do meio urbano. De acordo com Rodrigues, Pasqualetto e Garção (2017), a vegetação influencia no clima urbano por meio da oxigenação do ar, controle da poluição e fixação da poeira, do controle da umidade e da precipitação, da radiação solar. 
Observou-se que no meio antrópico os indicadores valorização imobiliária (30), paisagem urbana (24), tráfego (16), ventilação (28), qualidade de vida (23) foram consideradas com o nível de qualificação ideal. Destaca-se a valorização imobiliária (30), esse valor foi em consequência da localização das edificações no entorno da biodiversidade vegetal, recursos hídricos, quantidade de árvores do ponto de vista dos visitantes.

Em relação à qualidade de vida dos animais o impacto ficou em segundo lugar apresentando valor de 97 e terceiro lugar estresse (75). O estresse está relacionado com os animais em confinamento, por conseguinte, afetando na qualidade de vida. Essa visão dos visitantes reflete o fato dos animais do parque Zoológico viverem em cativeiros e conforme Manfrim, Santos e Hiroki (2017), explicam que esse ambiente pode desencadear resposta emocional, ocasionando sinais de estresse, pois rompe a homeostasia do indivíduo, ou seja, falta de estado de equilíbrio de diversas funções.

Observou-se que os animais estavam em confinamento, local pequeno e contribuindo para má qualidade de vida, deixando o animal estressado por existir pouco espaço. Isso pode ser constatado que o tigre sempre movimentava de um lado para o outro, possivelmente pelo estresse. $\mathrm{O}$ estresse pode manifestar tanto fisiológico como comportamento tático para espécie. Ressalta-se também que os macacos estavam agitados nos seus recintos, provavelmente pelo mesmo motivo citado anteriormente. Animais em cativeiro vivem em ambientes denominados recintos, onde se deve ao máximo ter características como o habitat natural de cada espécie, trazendo o maior conforto e bem-estar possível (Leira, et al., 2017).

Por outro lado, a gestão do parque tem reproduzido a espécie da Ararajuba com sucesso, colaborando com a perpetuação da mesma, pois está quase em extinção na natureza, além disso, ocorre o enriquecimento ambiental para reduzir problemas psicológicos, por exemplo, o estresse. De acordo com Manfrim, Santos e Hiroki (2017), a técnica de enriquecimento é utilizada para diminuir o estresse, proporcionando melhor qualidade de vida e ajudar na mensuração do bemestar animal.

Comparando a priorização de impactos do meio biótico fauna que representa indicadores de confinamento (109) e qualidade de vida dos animais (97) com os indicadores do meio físico, constatou-se que o primeiro foi de maior gravidade de impacto, pois no meio físico não obteve nenhum valor com a priorização maior que 109 e 97 (Tabela 3). 
Tabela 3 - Goiânia (GO): Nível de satisfação dos visitantes quanto aos fatores ambientais e priorização dos impactos no Zoológico, 2019.

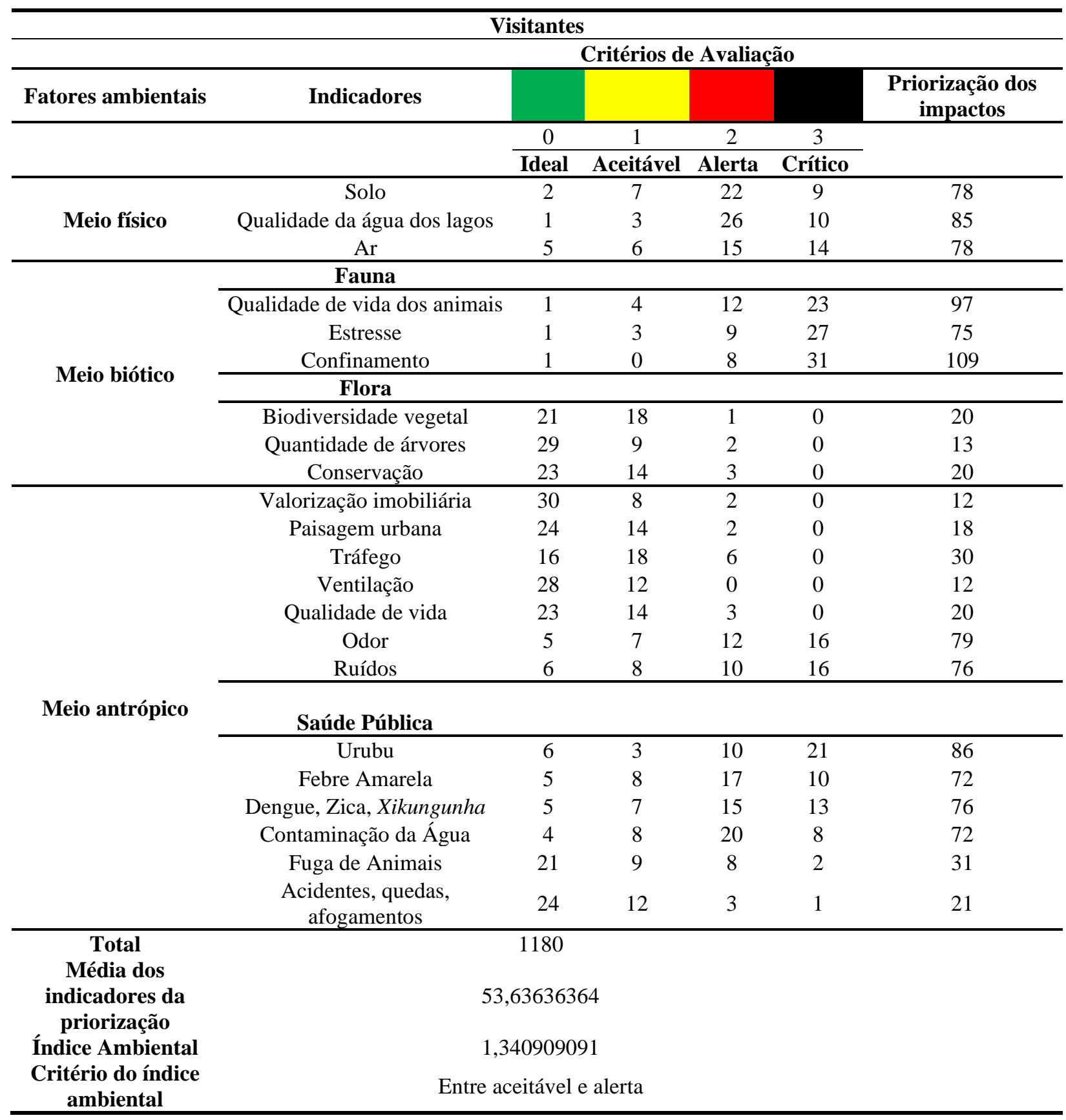

Fonte: Autores (2019).

Comparando-se todos os meios, notou-se que o meio antrópico, indicador acidentes, quedas e afogamentos (21), em relação a priorização foi de menor impacto na visão dos visitantes. Dessa forma, Leal, Carrerá e Pereira (2021) explica que a usando os indicadores quantifica informações contribuindo para formação de um índice de qualidade ambiental, retratando a capacidade das políticas urbanas se adequarem à oferta de serviços, à qualidade e à quantidade das demandas de serviços urbanos e investimentos em estrutura.

Quanto ao meio antrópico a dengue, Zica e Chikungunya ficou em segundo lugar (76) de maior impacto comparando com a dos urubus, trazendo risco à saúde pública. Quanto a saúde pública, o impacto maior (86) foi a presença de urubus, aumentando o risco de transmissão de doenças tanto aos animais quanto às pessoas. A existência de urubus pode estar relacionada à animais mortos no entorno do local, e outros resíduos sólidos, contaminando e poluindo o ambiente. A Lei $\mathrm{n}^{\circ}$ 
12.305 (2010) que aponta a Política Nacional de Resíduos Sólidos, sendo um dos princípios para se alcançar a sustentabilidade, destaca-se também que nessa política classifica os resíduos para o orientar o responsável do local, bem como a pessoa que elaborou o Plano de Gerenciamento de Resíduos Sólidos e assim fazer o destino final adequado dos resíduos sólidos.

O Plano de Gerenciamento de resíduos sólidos é feito por meio da separação do orgânico e reciclável. Resíduos orgânicos são constituídos pela fração orgânica dos resíduos sólidos, passível de compostagem, sejam de origem urbana, industrial, dentre outros. A Resolução CONAMA nº 481 (2017) define que os resíduos recicláveis são compostos pela fração de resíduos passíveis de reciclagem, com exceção dos resíduos orgânicos que podem ser reciclados por meio de compostagem.

O resíduo reciclável é recolhido pela coleta seletiva da COMURG (Companhia de Urbanização de Goiânia), é repassado para cooperativas de reciclagem. Para Kuhn, Botelho e Alves (2018), é perceptível que a coleta seletiva acaba estimulando a economia local, bem como a emancipação dos indivíduos por meio da possibilidade de geração de emprego e renda. O resíduo orgânico é depositado em containers e conduzido ao aterro sanitário de Goiânia.

Em visita "in loco" observou que dentro do Zoológico há coleta seletiva dos resíduos recicláveis, em vários locais tinham esse tipo de cestos e conservados. De acordo com Kuhn, Botelho e Alves (2018), a implementação da coleta seletiva proporciona vantagens ambientais, sociais e econômicas, por exemplo, a redução de custos com a disposição final do lixo (aterros sanitários ou incineradores), aumenta da vida útil de aterros sanitários, ampliação de indústrias recicladoras já estabelecidas (Vilhena, 2013).

A gestão do Parque Zoológico se preocupa com o gerenciamento de resíduos, cumprindo a Lei no 12.305 (2010) que institui a Política Nacional de Resíduos Sólidos. Um dos princípios da política é o desenvolvimento sustentável, o reconhecimento do resíduo sólido reutilizável e reciclável como um bem econômico e de valor social, gerador de trabalho e renda e promotor de cidadania, dentre outros.

Com esse plano implementado verificou-se também que o parque visa alcançar a sustentabilidade socioambiental, pois faz parceria no recolhimento dos resíduos gerados, consequentemente, gera trabalho às pessoas que realizam esse tipo de serviço. Conforme Brito, Cunha e Siveres (2018), a participação de todos os cidadãos é uma forma de alcançar ao sucesso à sustentabilidade do meio ambiente, pois o ser humano começa a se desenvolver de forma multifacetada e em comunidade, surgem ideias e maneiras de executar ações que provavelmente não teriam sido pensadas em termos individuais. Bem como, ações sustentáveis são sempre inovadoras e podem surgir de todas as faixas etárias, classes sociais e níveis de escolaridade, com isso, desenvolvendo atitudes e valores a fim de preservar o meio ambiente e a realização de ações práticas para a sustentabilidade.

O Zoológico atende ao Plano Diretor de Goiânia referente a Lei Complementar nº 171 (2007), com ação de coleta e destinação de resíduos via um sistema de gerenciamento seletivo, colaborando com a mitigação dos impactos ambientais. Ressaltou-se também que este local está de acordo com o capítulo II, artigo $7^{\circ}$ da Lei ${ }^{\circ} 12.305$ (2010), pois realiza reciclagem e tratamento dos resíduos sólidos, bem como disposição final; prioridade, nas aquisições e contratações governamentais para produtos reciclados e recicláveis, preocupando com a qualidade ambiental e o capítulo III da mesma lei, devido realizar planos de resíduos sólidos, coleta seletiva e educação ambiental.

Além disso, os resíduos orgânicos recolhidos são transportados para o aterro sanitário, atendendo a Lei $\mathrm{n}^{\circ} 12.305$ (2010), pois em seu conceito, a disposição final ambientalmente adequada é a distribuição ordenada de rejeitos em aterros, assim contribui para a redução da contaminação e dos impactos ambientais.

$\mathrm{Na}$ tabela 4 foram apresentadas as respostas de todos os moradores quanto aos impactos no meio físico, biótico e antrópico, com seus respectivos indicadores ambientais, bem como os critérios de avaliação e a priorização dos impactos. Em relação a flora, há boa quantidade de árvores para 55\% dos moradores, já que este fator foi considerado nível ideal. Porém, 5 pessoas dos 40 moradores criticaram a biodiversidade vegetal, ou seja, deveria existir mais espécies. Já o indicador de 
conservação do parque, dentro do critério de avaliação, foi considerado entre ideal (52,5\%) e aceitável (45\%). De acordo com Kunen, Tabalipa e Sabbi (2019, p. 2), "A flora e vegetação urbana trazem uma informação rica sobre as propriedades dos ecossistemas urbano".

Tabela 4 - Goiânia - GO: Nível de satisfação dos moradores quanto aos fatores ambientais e priorização dos impactos no Parque Zoológico, 2019.

Critérios de avaliação

\begin{tabular}{|c|c|c|c|c|c|c|}
\hline \multirow[t]{3}{*}{ Fatores ambientais } & \multirow[t]{3}{*}{ Indicadores } & & & & & \multirow{3}{*}{$\begin{array}{c}\text { Priorização dos } \\
\text { impactos }\end{array}$} \\
\hline & & 0 & 1 & 2 & 3 & \\
\hline & & Ideal & Aceitável & Alerta & Crítico & \\
\hline \multirow{3}{*}{ Meio físico } & Solo & 4 & 6 & 20 & 10 & 76 \\
\hline & Qualidade da água dos lagos & 0 & 5 & 19 & 16 & 91 \\
\hline & $\mathrm{Ar}$ & 3 & 4 & 20 & 13 & 83 \\
\hline \multirow{8}{*}{ Meio biótico } & Fauna & & & & & \\
\hline & Qualidade de vida dos animais & 0 & 5 & 14 & 21 & 96 \\
\hline & Estresse & 2 & 4 & 12 & 22 & 94 \\
\hline & Confinamento & 1 & 3 & 9 & 27 & 102 \\
\hline & Flora & & & & & \\
\hline & Biodiversidade vegetal & 16 & 17 & 2 & 5 & 36 \\
\hline & Quantidade de árvores & 22 & 16 & 2 & 0 & 20 \\
\hline & Conservação & 21 & 18 & 1 & 0 & 20 \\
\hline \multirow{14}{*}{ Meio antrópico } & Valorização imobiliária & 25 & 11 & 3 & 1 & 20 \\
\hline & Paisagem urbana & 25 & 8 & 6 & 1 & 23 \\
\hline & Tráfego & 12 & 20 & 5 & 3 & 39 \\
\hline & Ventilação & 27 & 12 & 1 & 0 & 14 \\
\hline & Qualidade de vida & 25 & 9 & 4 & 2 & 23 \\
\hline & Odor & 9 & 4 & 11 & 16 & 74 \\
\hline & Ruídos & 7 & 3 & 14 & 16 & 79 \\
\hline & \multicolumn{6}{|l|}{ Saúde Pública } \\
\hline & Urubu & 10 & 5 & 9 & 16 & 71 \\
\hline & Febre Amarela & 14 & 5 & 14 & 7 & 54 \\
\hline & Dengue, Zica, Xikungunha & 13 & 5 & 14 & 8 & 57 \\
\hline & Contaminação da Água & 12 & 7 & 9 & 12 & 61 \\
\hline & Fuga de Animais & 19 & 13 & 4 & 4 & 33 \\
\hline & Acidentes, quedas, afogamentos & 31 & 6 & 0 & 3 & 15 \\
\hline $\begin{array}{c}\text { Total } \\
\text { Média dos indicadores priorizados } \\
\text { Índice Ambiental } \\
\text { Critério do índice ambiental }\end{array}$ & & $\begin{array}{c}1181 \\
53,68181818 \\
1,342045455 \\
\text { e aceitável e a }\end{array}$ & & & & \\
\hline
\end{tabular}

Fonte: Autores (2019). 
Ainda na Tabela 4, observou-se que a valorização imobiliária (62,5\% e 27,5\%), paisagem urbana (62,5\% e 20\%), tráfego (30\% e 50\%), ventilação $(67,5 \%$ e $30 \%)$, qualidade de vida $(62,5 \%$ e $22,5 \%)$ não são vistas como problema para os moradores, traduzindo predominância das respostas em nível de ideal e aceitável, respectivamente, no meio antrópico.

Destacando-se que a maior preocupação foi a questão de odor e ruídos, ambos representados por $40 \%$ para nível crítico e o nível de alerta foi $30 \%$ e $25 \%$ para odor e ruído, respectivamente. Consequentemente, está relacionado aos odores e barulhos de animais, pertinentes ao parque Zoológico. Porém, durante visita à campo, os ruídos foram cantos das aves e barulhos de macacos, estes não chegam a incomodar quem visita o parque. Quanto ao odor no momento da visita não se detectou mau cheiro no local.

Quanto à saúde pública, muitos responderam que a presença de urubus está numa situação de alerta $(22,5 \%)$ e crítico (40\%), embora $25 \%$ não tenham a percepção respondendo como ideal, talvez porque estas pessoas não costumam olhar para cima no entorno do local ou os urubus não as perturbem. Do total, 25 moradores, 62,5\% se sentem incomodados com a presença de urubus, não só pelo risco de transmissão de doenças, mas também porque estes animais acabam bebendo água nas piscinas no local em que os moradores residem, pousando e defecando, além de causar outros transtornos como assustando as pessoas.

Analisando-se a hierarquização dos impactos observou-se que o impacto mais grave verificado pelos moradores foi o confinamento (102), em segundo lugar, a qualidade de vida dos animais (96), em terceiro lugar o estresse da fauna (94), portanto todos relacionados ao meio biótico fauna. Verificou-se que os impactos analisados fazem parte da diretriz que está classificada quanto à abordagem de acordo com a Resolução CONAMA n ${ }^{\circ} 422$ (2010), essa retrata dos impactos socioambientais provocados pelas atividades antrópicas e as responsabilidades humanas na manutenção da segurança ambiental e da qualidade de vida.

No Gráfico 1 mostra-se a visão do modelo de animais presos existente no parque Zoológico de Goiânia, com resultados percentuais de visitantes e moradores. Tanto os visitantes (17\%) quanto moradores (20\%) não preferem animais presos, respectivamente. Entretanto, 68\% das 27 pessoas de cada grupo em que opinaram sobre modelos relacionados ao equipamento urbano de lazer sugerem um outro modelo de parque Zoológico, por exemplo, Safari. De acordo Silva, Nunes e Pequeno (2015) o modelo de zoológico Safari iniciou-se o primeiro com o colonialismo da Europa sobre a África, termo originado no suaíli que é uma das principais línguas da África central, significando uma jornada ou expedição na selva, com o objetivo de visita, fotografia ou caçada, mas também para interesse científico.

Dessa forma, define-se Safari em que os animais não vivem em cativeiros, ficam livres, os visitantes são transportados pelas vans, ônibus ou carro para realizar a visita no local. Das 80 pessoas que responderam questionário, 11 preferem o modelo de animais presos, significa $15 \%$ dos 6 visitantes e $12 \%$ de 5 moradores, totalizando 40 pessoas de cada grupo (Gráfico 1). 
Gráfico 1 - Goiânia (GO): Nível de satisfação dos visitantes e moradores em relação ao modelo de animais presos no Parque Zoológico, 2019.

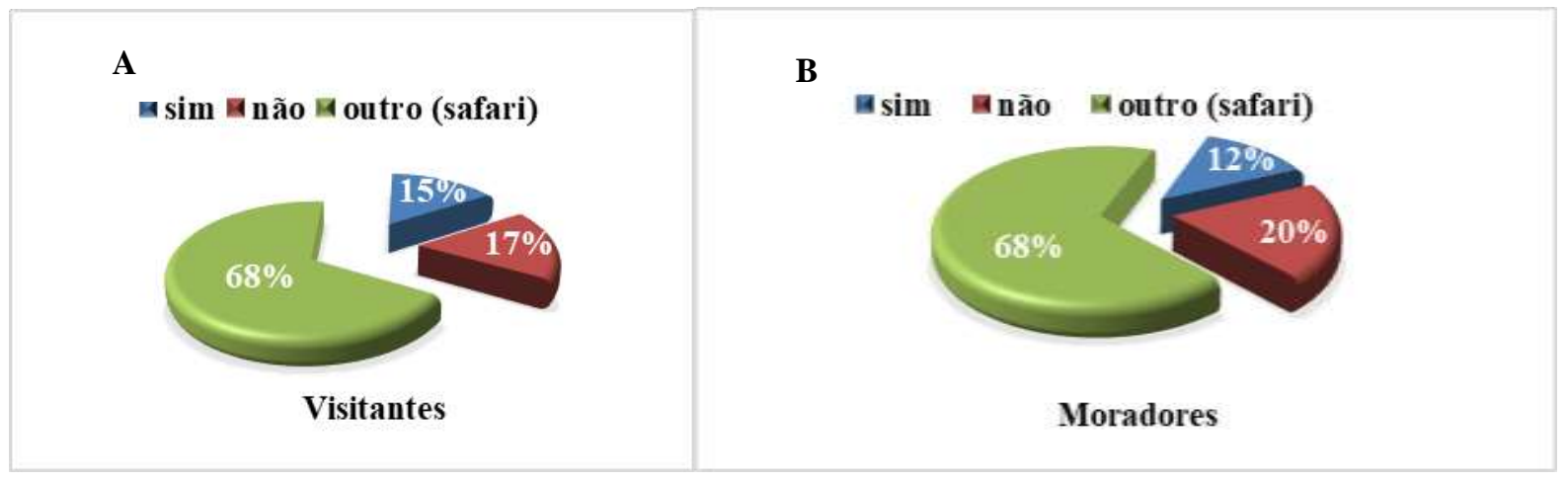

Fonte: Autores (2019).

No Gráfico 2, 53\% dos moradores e 60\% visitantes consideraram que o Parque Zoológico de Goiânia está localizado adequadamente. Restando 19 e 16 pessoas que foram contra a localização desse local, representando na forma percentual $48 \%$ e 40\%, respectivamente. Logo, 45 pessoas do total de 80 consideraram o local adequado. Goyaz (1984), afirma que é viável a permanência do mesmo no local em que se encontra por mais algum tempo, ou seja, Setor Oeste, ainda retratou que com o decorrer do tempo a poluição sonora e ambiental chegará a níveis não aconselháveis ao zoológico.

Deve-se avaliar todos os impactos ambientais presentes no local e no entorno do equipamento urbano para verificar os níveis dos mesmos, mas também o espaço em que os animais vivem e se há formas para ampliação, caso contrário, seria viável estudar nova área para possibilidade de transferência do Parque Zoológico de Goiânia. Conforme apresentado no Relatório Preliminar Para Comissão (1974) o paisagista Cordeiro afirma que: "se o zoológico permanecer na parte sul do Lago das Rosas (local atual) teria reduzidas condições de expansão, desaconselhando-se sua permanência”.

O Parque Zoológico proporciona a educação ambiental, atendendo aos requisitos da Constituição da República Federativa do Brasil. A Constituição da República Federativa do Brasil (1988), expõe no artigo 225, inciso VI que: "promover a educação ambiental em todos os níveis de ensino e a conscientização pública para a preservação do meio ambiente", conscientizando a população para a proteção da fauna e flora, cumprindo outro inciso do mesmo artigo "proteger a fauna e a flora, vedadas, na forma da lei, as práticas que coloquem em risco sua função ecológica, provoquem a extinção de espécies ou submetam os animais a crueldade".

Ainda no Gráfico 2 quanto à existência do equipamento urbano de lazer, $78 \%$ dos moradores e $85 \%$ dos visitantes acham necessário haver o parque, porém para $23 \%$ e 15\%, respectivamente, não há necessidade de ser este local. A existência do Parque Zoológico proporciona lazer para a população, além de conhecer várias espécies de animais ampliando os conhecimentos, mas também estar em contato com a natureza, área verde, consequentemente, regularizando a temperatura do ambiente, ou seja, quanto maior concentração de vegetação, maior redução da temperatura do meio urbano, tornando-se o ambiente fresco e confortável. Assim sendo, um espaço maior poderia atender tanto aos animais como aos anseios da população. 
Gráfico 2 - Goiânia (GO): Visão da população sobre a localização e existência do Parque Zoológico, 2019.

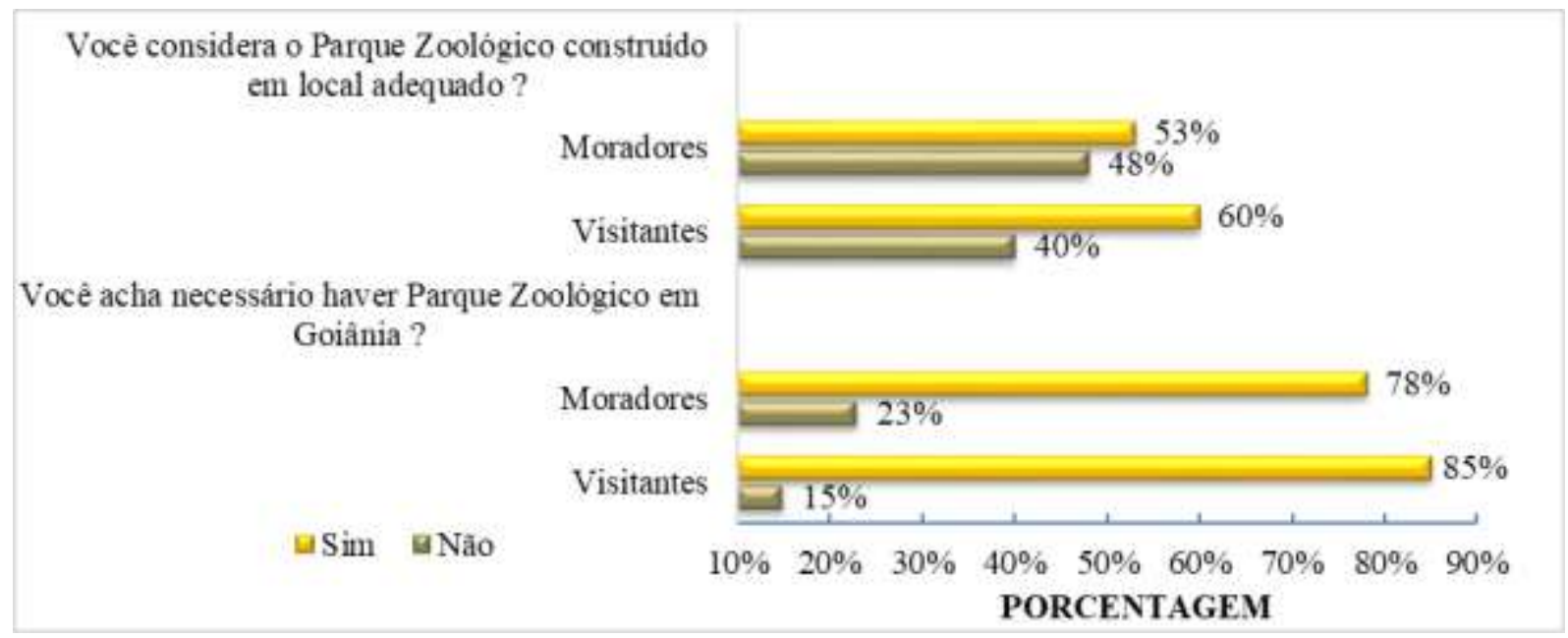

Fonte: Autores (2019).

Há ideia de transferência do local sendo avaliada a possibilidade de se planejar em alguma área fora do perímetro urbano um novo conceito de zoológico; mais moderno. Ressalta-se que as áreas do Jardim Botânico de Goiânia e do Parque Estadual Altamiro de Moura Pacheco foram descartadas.

Abreu (2017), relata que a área analisada foi na região Norte, especificamente, Setor Santa Genoveva, nas proximidades do Clube Antônio Ferreira Pacheco, do Serviço Social da Indústria (Sesi), há duas áreas em vista para a transferência do local, uma sendo do Estado, porém precisa verificar a disponibilidade de doação ou concessão à Prefeitura ou parceria.

A outra opção seria doação de área particular, pertencendo a um grupo de empresários e em torno de 14 alqueires. Abreu (2017), informou a ideia do desejo de se fazer em Goiânia o maior Zoológico do Brasil, apenas com animais do Cerrado, para isso é necessário montar toda estrutura específica, sendo mais simples fazer em área nova, do que adaptar o que existe atualmente (2021).

Ademais, ainda explica que com essa ideia poder-se-ia conseguir investimentos e parcerias de empresas atuando na conservação de biomas brasileiros. A solução para os animais de outros biomas seria realizar a doação ou serem trocados com outros zoológicos do país, em busca de mais espécies de animais do Cerrado.

\section{Considerações Finais}

O Parque Zoológico foi inaugurado quatro anos após a fundação de Goiânia (1942 - 1946), e desde então passou por várias reformas e alterações em sua infraestrutura na época em que ocorria o crescimento urbano em ritmo acelerado no município de Goiânia. Sem critérios urbanísticos, acarretou em problemas ambientais e urbanos.

Os impactos mais relevantes ocorrem sobre o meio físico, especialmente relacionados aos confinamentos dos animais e as consequências associadas às práticas. No meio físico, preocupação deve se voltar principalmente para a qualidade das águas. Quanto ao meio antrópico, atenção à saúde pública deve ser priorizada.

A maioria dos moradores e visitantes compreendeu que o local do Parque Zoológico é adequado, porém preferem o modelo Safari: animais livres; sem o sofrimento dos cativeiros, influenciando na qualidade de vida dos mesmos, e possivelmente em um outro local, requerendo área maior, sendo um diferencial na região de Goiás por não existir esse tipo de parque no Centro-Oeste Brasileiro. 
Várias áreas foram estudadas para a possível transferência do parque Zoológico de Goiânia, mas sem sucesso. Como não ocorreu a transferência, a proposta sugerida para trabalhos futuros seria realizar um estudo com a possibilidade de se ter um parque apenas com animais do Cerrado, seria uma forma de reduzir problemas existentes, principalmente para os animais exóticos que vivem em cativeiros e que não são adaptados ao clima de Goiânia.

Outra sugestão para trabalhos futuros seria verificar a possibilidade de implantar o parque Zoológico no modelo Safari em Goiânia ou em região metropolitana de Goiânia, sendo um diferencial na região de Goiás por não existir esse tipo de parque e por ser a preferência da maioria dos visitantes e moradores utilizando o Sistema de Informações Geográficas, por exemplo, geoprocessamento e outras metodologias.

\section{Agradecimentos}

Agradecimentos a CAPES - Coordenação de Aperfeiçoamento de Pessoal de Nível Superior.

\section{Referências}

Abreu, V. (2017, 9 dezembro). Agetul vai propor novo ZooGyn. O Popular. https://www.opopular.com.br/noticias/cidades/agetul-vai-propor-novo-zoogyn1.1414097

Bellen, H. M. V. (2005). Indicadores de Sustentabilidade: uma análise comparativa. FGV.

Brito, R.O., Cunha, C., \& Siveres, L. (2018). Gestão participativa e sustentabilidade socioambiental: um estudo em escolas da rede pública de Sobral-CE. Ciência \& Educação, 24 (2), 395-410. https://doi.org/10.1590/1516-731320180020009

Comissão Parque Educativo (Zoológico e Lago das Rosas) (1974). Relatório Preliminar, 28 mai. 1975. In: SEPLAM. Documentos relacionados ao Parque Zoológico, Goiânia: SEPLAM, 2018.

Constituição da República Federativa do Brasil de 1988. Congresso Nacional. http://www.planalto.gov.br/ccivil_03/constituicao/constituicao.htm

Gomes, L.P., Peruzatto, M., Santos, V. S., \& Sellito, M. A. (2014). Indicadores de sustentabilidade na avaliação de granjas suinícolas. Revista Engenharia Sanitária e Ambiental, 19(2), 143-54. https://doi.org/10.1590/S1413-41522014000200005.

Goyaz, P.A.G. (1984). Projeto Jardim Zoológico. Goiânia: Iplan.

Instituto Brasileiro de Geografia e Estatísticas (2017). Estatística Populacional: 2017. https://cidades.ibge.gov.br/brasil/go/goiania/panorama

Instituto Brasileiro de Geografia e Estatísticas (2018). Base Cartográfica. IBGE.

Kuhn, N., Botelho, L. L. R., \& Alves, A. A. A. (2018). A coleta seletiva à luz da PNRS nos estados brasileiros: uma revisão sistemática integrativa. Revista Brasileira de Planejamento e Desenvolvimento, 7 (5), 646-69. 10.3895/rbpd.v7n5.7628

Kunen, A., Tabalipa, N.L., \& Sabbi, V. (2019). Análise da vegetação a partir de dados de sensoriamento remoto multitemporal no município de Pato BrancoPR. Revista Brasileira de Planejamento e Desenvolvimento, 8 (3), 433-56. http://dx.doi.org/10.3895/rbpd.v8n3.8928

Leal, A.G.L., Carrerá, Y.A., \& Junior, A.P. (2021). Elaboração e análise comparativa do índice de qualidade ambiental em núcleos urbanos. Research, Society and Development, 10 (10), e 510101019142, 1-18. http://dx.doi.org/10.33448/rsd-v10i10.19142

Lei Complementar $n^{\circ} .171$ de 29 de maio de 2007. Dispõe sobre o Plano Diretor e o processo de planejamento urbano do Município de Goiânia e dá outras providências. Prefeitura Municipal. https://www.goiania.go.gov.br/html/gabinete_civil/sileg/dados/legis/2007/lc_20070529_000000171.html

Lei $n^{\circ}$ 12.305, de 2 de agosto de 2010. Institui a Política Nacional de Resíduos Sólidos, altera a lei n. ${ }^{\circ} 9.605$, de 12 de fevereiro de 1998 , e dá outras providências. Presidência da República. http://www.planalto.gov.br/ccivil_03/_ato2007-2010/2010/lei/112305.htm

Leira, M. H., Reghim, L. S., Cunha, L. T., Ortiz, L. S., Paiva, C. O., Botelho, H. A., Ciacci, L. S., Braz, M. S., \& Dias, N. P. P. (2017). Bem-estar dos animais nos zoológicos e a bioética ambiental. Revista Pubvet - Medicina Veterinária e Zootecnia, 11 (7), 545-53. https://www.pubvet.com.br/artigo/3906/bem-estardos-animais-nos-zooloacutegicos-e-a-bioeacutetica-ambiental

Levine, D. M., Berenson, M. L., \& Stephan, D. (2000). Estatística: Teoria e Aplicações. LTC.

Macedo, L. O. B., Cândido, G. A., Costa, C. G. A., \& Silva, J. V. F. (2016). Avaliação de sustentabilidade dos municípios do estado de Mato Grosso mediante o emprego do IDSM - Índice de Desenvolvimento Sustentável para municípios. Revista Brasileira de Gestão e Desenvolvimento Regional, 12 (3) 323-45. Recuperado de https://www.rbgdr.net/revista/index.php/rbgdr/article/view/2530

Manfrim, T., Santos, C. M., \& Hiroki, K. A. N. (2017). Avaliação da influência das técnicas de enriquecimento ambiental nos parâmetros comportamentais de um casal de Jaguatiricas (Leopardus pardalis, Linnaeus, 1758) mantidos em cativeiro no parque do jacarandá (zoológico municipal de Uberaba, Minas Gerais). Revista Brasileira de Zoociências, 18 (1), 103-120. https://doi.org/10.34019/2596-3325.2017.v18.24665 
Martins, M. F., Salles, M. C. T., Macedo, T. E., Nunes, E.R., \& Ribeiro, R. O. (2020). Problemas urbanos que interferem na sustentabilidade de cidades: um estudo no Município de Serra Redonda-Paraíba-Brasil. Research, Society and Development, 9 (8), e730986177. https://doi.org/10.33448/rsd-v9i8.6177

Molina, F. R. (2016). Zoológico de Buenos Aires é fechado após 140 anos, Internacional. El País. https://brasil.elpais.com/brasil/2016/06/23/internacional/1466689780_228888.html

Montes, M. F., \& N. Filho, G. A. (2009). Água como indicador ambiental. In: Neumann-Leitão, S., \& El-Deir, S. G. (Org). Bioindicadores da Qualidade Ambiental. Recife: Instituto Brasileiro Pró-Cidadania.

Nascimento, D. T. F., \& Oliveira, I. J. (2015). Mapeamento do processo histórico de expansão urbana do município de Goiânia-Go. Revista Geographia, 17 (34), 141-67. https://doi.org/10.22409/GEOgraphia2015.v17i34.a13715

Patra, S., Sahoo, S., Mishra, P., \& Mahapatra, S. C. (2018). Impacts of urbanization on land use cover changes and its probable implications on local climate and groundwater level. Journal of Urban Management, Hangzhou, 7 (2), 70-84. https://doi.org/10.1016/j.jum.2018.04.006

Resolução $n^{\circ}$ 422, de 23 de março de 2010. Estabelece diretrizes para as campanhas, ações e projetos de Educação Ambiental, conforme Lei no 9.795 , de 27 de abril de 1999, e dá outras providências, do Conselho Nacional do Meio Ambiente - CONAMA. http://conama.mma.gov.br/?option=com_sisconama\&task=arquivo.download\&id=603

Resolução $n^{o}$ 481, de 03 de outubro de 2017. Estabelece critérios e procedimentos para garantir o controle e a qualidade ambiental do processo de compostagem de resíduos orgânicos, e dá outras providência, do Conselho Nacional do Meio Ambiente - CONAMA. http://conama.mma.gov.br/?option=com_sisconama\&task=arquivo.download\&id=702

Ribeiro, R., et al. (2009). Zôo São Paulo: 50 anos de História da Fundação Parque Zoológico de São Paulo. São Paulo: Instituto Libenter de Integração Social, Educação, Cultura e Desenvolvimento Humano.

Rodrigues, A. P. M., Pasqualetto, A., \& Garção, A. L. O. (2017). A influência dos parques urbanos no microclima de Goiânia. Revista Baru, Goiânia, 3 (1), 25-44. http://dx.doi.org/10.18224/baru.v3i1.5829

Severino, J. A. (2016). Metodologia do Trabalho Científico. (24a ed). Cortez.

Silva, A. C. P., Nunes, M. F., \& Pequeno, M. J. P. (2015). Um percurso pela Filosofia Prática e História das Ciências sobre a constituição dos zoológicos como espaços de lazer e de musealização científica. Revista Iberoamericana de Turismo (RITUR), Penedo, 5 (1), 147-69. https://www.seer.ufal.br/index.php/ritur/article/view/1817

Silva, G. C. O. (2017). Uso de instrumentos da gestão do risco de cheias como ferramenta no planejamento urbano. 278p. Tese (Doutorado). Universidade Federal do Rio de Janeiro, Instituto Alberto Luiz Coimbra, 2017. http://hdl.handle.net/11422/7333

Silva, J. L. C., Vidal, C. A. S., Barros, L. M., \& Freitas, F. R. V. (2018). Aspectos da degradação ambiental no Nordeste do Brasil. Revista Gestão \& Sustentabilidade Ambiental, 7 (2), 180-191. http://dx.doi.org/10.19177/rgsa.v7e22018180-191

Vale, F. A. F., Toledo, P. M., \& Vieira, I. C. G. (2018). Análise comparativa de indicadores de sustentabilidade entre os estados da Amazônia Legal. Sustentabilidade em Debate, 9 (1) 214-31. https://doi.org/10.18472/SustDeb.v9n1.2018.25621

Vilhena, A. (2013). Guia da coleta seletiva de lixo. Compromisso Empresarial para Reciclagem. 